\title{
The Role of Class Diagram in Estimating Software Size
}

\author{
Mohammad Harizi \\ Computer department, Islamic Azad University, Ramhormoz Branch, Iran
}

\begin{abstract}
One of the subjects related to software engineering is software measurement. Software measurement itself includes different topics that estimating software size is one of them. Various methods have been proposed for estimating software size. Each studies this topic from specific approach. Since UML is a well-known notation for representing object-oriented models, some of the methods are based on it. In this article, through describing class diagram, we consider the efficacy and role of class diagram in estimating software size.
\end{abstract}

\section{Keywords}

Software Measurement, Software size estimation, UML class diagram, Analysis object model, Static Modeling

\section{INTRODUCTION}

Generally, the process of software engineering includes 4 stages: Analysis, Design, Implementation and Support. One of the subjects related to software engineering is software measurement. Software measurement has become essential to good software engineering. Measurement is the process by which numbers or symbols are assigned to attributes of entities in the real world in such a way as to describe them according to clearly defined rules. Many of the best software developers measure characteristics of the software to get some sense of whether the requirements are consistent and complete, whether the design has high quality, and whether the code is ready for test. Effective managers of project measure attributes of process and product to be able to tell when the software will be ready for delivery and whether the budget will be exceeded. Software measurement is not a mainstream topic within software engineering. Rather it is a diverse collection of fringe topics (generally referred to as software metrics) that range from models for predicting software project costs at the specification stage to measure program structure [1].

Two important words within software metrics are effort and size. Effort is expressed as a function of one or more variables (such as size of product, capability of the developers and level of reuse). Size is usually defined as lines of code or number of function points (which may be derived from the product specification) [1], [2].

\section{THE SOFTWARE MEASUREMENT MODELS}

One of the activities of software metrics is costs and effort estimation. Numerous models for this activity have been proposed and used. Examples include Boehm's COCOMO model, Putnam's SLIM model and Albrecht's FP model.

The models may be done in the end of software development project by counting the number of lines of code. Also, methods like function points have been designed to be served in the beginning of development. In this article, the idea of estimating software size is nearly in the middle of development process (Analysis Object Model) based on class diagram discussed in UML.

However, why in the middle of the development process? In our opinion, estimating software size in the middle of development can attain results more believably. Therefore, depending on these results is seemed more logical. To reach to this important, as it is mentioned, we use class diagram notation introduced in UML.

\section{THE PLACE OF CLASS DIAGRAM IN UML}

The goal of UML is to provide a standard notation that can be used by all abject-oriented methods and to select and integrate the best elements of precursor notations. System development focuses on 3 different models of the system [3]:

1. The functional model represented in UML use case diagrams.

2. The object model or static model represented in UML with class diagrams.

3. The dynamic model represented in UML with interaction diagrams, state-chart diagrams, and activity diagrams.

Class diagrams are used to describe the structure of the system. Classes are abstractions that specify the common structure and behavior of a set of objects. Objects are instances of classes that are created, modified, and destroyed during the execution of the system. An object has a state that includes the values of its attributes and its links with other objects [3]. Class diagrams are built during analysis and in object model. Above models represent user-level concepts, not actual software classes or components.

In [4] and [5], sequentially based on interaction diagrams like actor-object sequence diagrams and use case diagrams, the action of estimating software size has been discussed. Also in [6], various parameters have been introduced among in class part for measuring size of software. However, it is nowhere expressed about class diagram efficacy in this fact comprehensively.

In this article, we carefully focus on object model or static concepts of model and survey the role of class diagram for estimate software size with great detail. Class diagram describes the static structure of the system, and this fact can extremely be suitable in calculating the size of software.

We need to recognize two aspects in modeling classes:

- To denote attributes and operations for each class, 
- To denote the relationships state among classes.

Attributes can be defined as public, private or protected. Operations can be defined with some inputs and outputs. Associations are relationships between classes and represent group of links (connections between objects). Associations can be symmetrical or asymmetrical; also they can have attributes and operations like classes (named Association class). In association basis, it is posed multiplicity types as one-to-one, one-to-many, and many-to-many that latter is the most complex type of association. Also, inheritance and aggregation are other relationships between classes which discussed in following.

In inheritance relationship, we face with super-class or abstract class and sub-class concepts. In figure 1 to 3 , mentioned topics have been shown.

\begin{tabular}{|c|c|c|}
\hline Class A & An & Class B \\
$\begin{array}{c}\text { Some attributes } \\
\text { definition }\end{array}$ & $\begin{array}{c}\text { Association } \\
\text { Relationship }\end{array}$ & $\begin{array}{c}\text { Some attributes } \\
\text { definition }\end{array}$ \\
$\begin{array}{c}\text { Some operations } \\
\text { definition }\end{array}$ & & $\begin{array}{c}\text { Some operations } \\
\text { definition }\end{array}$ \\
\hline
\end{tabular}

Multiplicity A Multiplicity B

Fig 1: Example of an association between two classes

An Aggregation

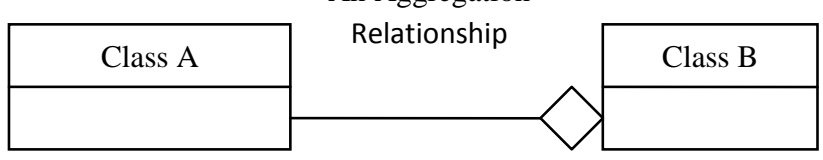

Fig 2: Example of an aggregation relationship between two classes

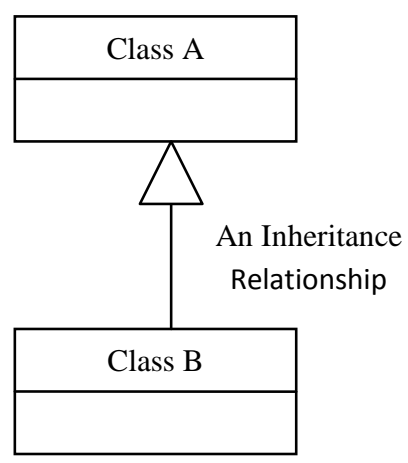

Fig 3: Example of inheritance relationship between two classes

\section{USING CLASS DIAGRAM FOR ESTIMATING SOFTWARE SIZE}

As a result, following parameters are introduced concerning class diagrams. For each parameter, a weight can be assigned. The list of parameters is mentioned in table 1 .
Table 1: The list of parameters

\begin{tabular}{|c|c|c|}
\hline & Parameter name & Weight \\
\hline 1 & $\begin{array}{c}\text { Number of class public } \\
\text { attributes(NPA) }\end{array}$ & 1 \\
\hline 2 & $\begin{array}{c}\text { Number of class private } \\
\text { attributes(NPRA) }\end{array}$ & 0.5 \\
\hline 3 & $\begin{array}{c}\text { Number of class protected } \\
\text { attributes(NPTA) }\end{array}$ & 1 \\
\hline 4 & Number of class operations(NOP) & 2 \\
\hline 5 & $\begin{array}{c}\text { Number of class operations } \\
\text { inputs(NOI) }\end{array}$ & 1 \\
\hline 6 & $\begin{array}{c}\text { Number of class operations } \\
\text { outputs(NOO) }\end{array}$ & 1 \\
\hline 7 & Number of class methods(NHM) & 3 \\
\hline 8 & Number of class methods inputs(NMI) & 1 \\
\hline 9 & $\begin{array}{c}\text { Number of class methods } \\
\text { outputs(NMO) }\end{array}$ & 1 \\
\hline 10 & Number of class associations(NAS) & 2 \\
\hline 11 & $\begin{array}{c}\text { Number of class symmetrical } \\
\text { associations(NSA) }\end{array}$ & 1 \\
\hline 12 & $\begin{array}{c}\text { Number of class asymmetrical } \\
\text { associations(NAA) }\end{array}$ & 1.5 \\
\hline 13 & $\begin{array}{l}\text { Number of class one-to-one } \\
\text { cardinality(NOO) }\end{array}$ & 1 \\
\hline 14 & $\begin{array}{c}\text { Number of class one-to-many } \\
\text { cardinality(NOM) }\end{array}$ & 2 \\
\hline 15 & $\begin{array}{c}\text { Number of class many-to-many } \\
\text { cardinality (NMM) }\end{array}$ & 3 \\
\hline 16 & $\begin{array}{l}\text { Number of class aggregation } \\
\text { relationships(NAR) }\end{array}$ & 2 \\
\hline 17 & $\begin{array}{c}\text { Number of class inheritance } \\
\text { relationships(NIR) }\end{array}$ & 2 \\
\hline 18 & Class depth in diagram(CDD) & 1 \\
\hline
\end{tabular}

The weights have been determined on the basis of their importance, complexity and the potency of the use in class modeling concepts. For example, since an asymmetrical association has more complexity than a symmetrical association, its weight is too more than the weight of symmetrical association.

For each class available in class diagrams, the values of parameters are calculated and adding them, the size of that class is obtained. Then, for all classes, this procedure is done and total size is calculated. The example below, with respect to the above parameters, we calculate the size of class A. Details of the estimation have been mentioned in figure 4. 


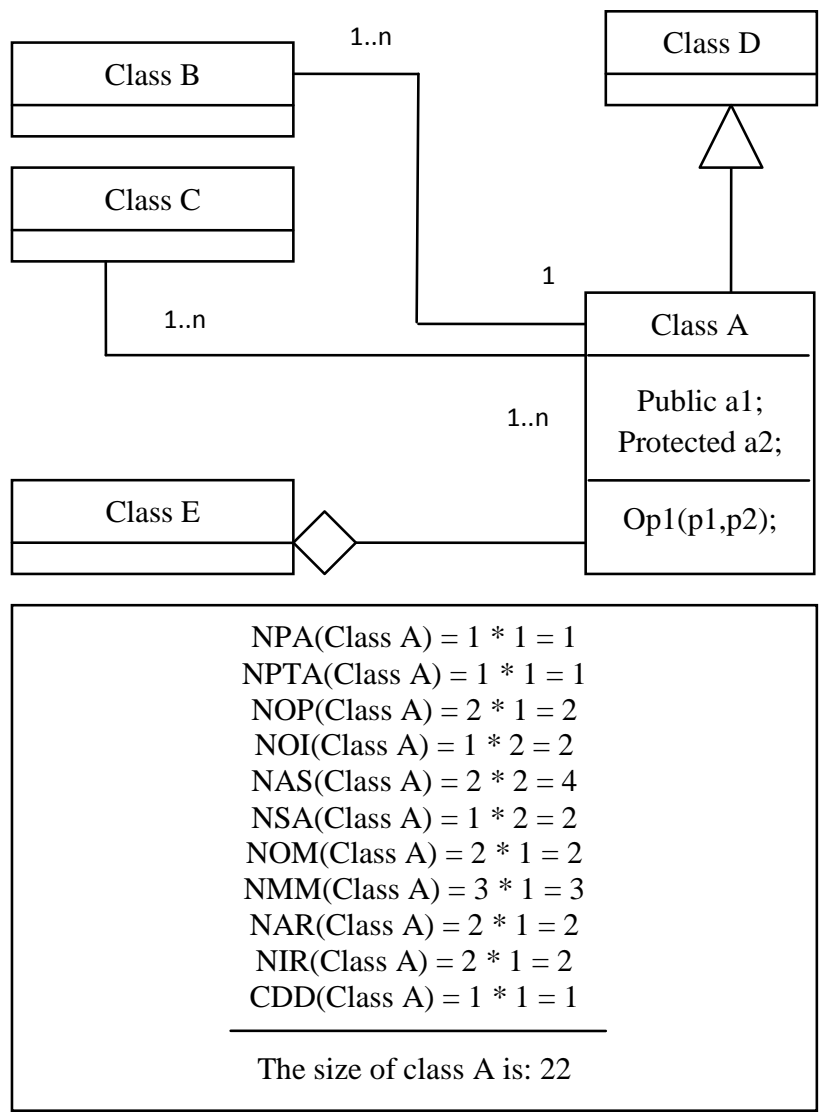

Fig 4: Example of calculating the size of one class

\section{CONCLUSION}

In this article, through introducing class diagram that is a notation of UML, we attempted to discuss the efficacy and role of class diagram in estimating software size which is one of the topics in software measurement. We presented the parameters, based on indicated diagram, which can provide a model for software size estimation.

\section{ACKNOWLEDGMENTS}

With thanks to my parents and my wife. This article has been resulted from the research plan on Islamic Azad University, Ramhormoz branch.

\section{REFERENCES}

[1] Norman E. Fenton, Shari Lawrence Pfleeger. "Software Metrics". PWS Publishing Company, 1997.

[2] Harizi Mohammad. "Presenting a Comprehensive Method on Software Size Estimation". Research Plan, 52304890508004. Islamic Azad University, Ramhormoz Branch. 2011.

[3] Bernd Bruegge, Allen H. Dutoit. "Object-Oriented Software Engineering". Pearson Prentice Hall, 2004.

[4] Ghislain Levesque, Valery Bevo, De Tran Cao. "Estimating Software Size with UML Models"; ACM, C3S2E-08, May 12-13, 2008.

[5] Benta Anda, Hege Dreiem, Dag I.K. Sjoberg, Magne Jorgensen. "Estimating Software Development Effort based on Use Cases - Experiences from Industry"; UML 2001: 487-502, October 1-5, 2001.

[6] Hyoseob Kim, Cornelia Boldyreff. "Developing Software Metrics Applicable to UML Models". 6th ECOOP Workshop on Quantitative Approaches in Object-Oriented Software Engineering, June 11th, 2002. 